\title{
Analisis Pemilihan Rekomendasi Produk Asuransi Jiwasraya Berdasarkan Kebutuhan Nasabah Menggunakan Metode Simple Additive Weighting (SAW)
}

\author{
Lis Saumi Ramdhani ${ }^{1}$, Dewi Qomara ${ }^{2}$, Erika Mutiara ${ }^{3}$, Jamal Maulana Hudin ${ }^{4}$ \\ 1,2,3,4 Universitas Bina Sarana Informatika \\ e-mail: ${ }^{1}$ lis.lud@bsi.ac.id, ${ }^{2}$ dewiqomara77@gmail.com, ${ }^{3}$ erika.emb@bsi.ac.id, \\ 4Jamal.jml@bsi.ac.id
}

\begin{abstract}
Abstrak
Dengan semakin berkembangnya asuransi tentunya semakin banyaknya program yang ditawarkan, sehingga semakin menjadi daya tarik bagi calon nasabah yang ingin meggunakan jasa asuransi. Untuk setiap calon nasabah, program asuransi yang mereka butuhkan pasti berbeda. Sebagian calon nasabah sering dihadapkan dengan masalah dalam memilih produk asuransi yang sesuai dengan kebutuhan dan kurangnya pemahaman nasabah terhadap produk yang ditawarkan. Untuk itu dalam memilih produk yang tepat dan sesuai dengan kebutuhan, diperlukan suatu sistem pendukung keputusan yang dapat memperrmudah nasabah dalam mendapatkan informasi serta dapat membantu calon nasabah dalam memahami asuransi agar tidak keliru dalam memilih produk yang sesuai dengan kebutuhan. Sistem pendukung keputusan yang dibuat menggunakan metode SAW (Simple Additive Weighting) dimana kriteria yang digunakan berjumlah lima kriteria, yaitu usia, manfaat, kegunaan, masa pertanggungan dan cara bayar. Hasil yang diperoleh dari penelitian berupa hasil perangkingan pada setiap alternatif yang akan dijadikan sebagai alternatif terpilih dalam pemilihan produk asuransi yaitu produk asuransi Js Optima Assurance terpilih sebagai alternatif pertama dengan perolehan nilai tertinggi yaitu 82.
\end{abstract}

Keywords: Sistem Pendukung Keputusan (SPK), Simple Additive Weighting (SAW), Asuransi

\begin{abstract}
At the moment Insurance growth is growing, so the number of programs offered is an attraction for candidates who want to use insurance services. For every prospective buyer, the insurance program they need must be different. Most prospective customers are often faced with the problem of choosing an insurance product that suits their needs and appreciates the understanding of the products offered. For that, in choosing products that are appropriate and in accordance with needs, a decision support system is needed that can trust in getting information and can help prospective buyers in ensuring insurance so they may not choose in choosing products that suit their needs. Decision support systems are made using the SAW (Simple Additive Weighting) method where the criteria used support five criteria, namely age, benefits, usability, insurance period and method of payment. The results obtained from the study consist of the results of ranking on each alternative that will be taken as an alternative chosen in the selection of insurance products.
\end{abstract}

Keywords: Decision Support System (SPK), Simple Additive Weighting (SAW), Insurance

\section{Pendahuluan}

Asuransi merupakan suatu bentuk pengendalian resiko, kemampuan untuk menetapkan kerugian-kerugian kecil yang sudah pasti sebagai pengganti atau substitusi kerugian-kerugian besar yang belum terjadi. Asuransi adalah istilah yang digunakan untuk merujuk pada tindakan, sistem atau bisnis dimana perlindungan finansial (ganti rugi) untuk jiwa, property, kesehatan dan lainya (Gunawan, 2014). 
Dalam Undang-Undang Nomor 2 Tahun 1992 tentang usaha perasuransian adalah perjanjian antara dua pihak atau lebih, dimana pihak penanggung mengikatkan diri kepada tertanggung, dengan menerima premi asuransi, untuk memberikan pergantian kepada tertanggung karena kerugian, kerusakan atau kehilangan keuntungan yang diharapkan atau tanggung jawab hukum pihak ketiga yang mungkin akan diderita tertanggung, yang timbul dari suatu peristiwa yang tidak pasti, atau memberikan suatu pembayaran yang didasarkan atas meninggal atau hidupnya seseorang yang dipertanggungkan.

Pada saat ini pertumbuhan usaha asuransi semakin pesat berkembang, Dengan begitu banyak nya program yang ditawarkan tentunya menjadi daya tarik bagi calon nasabah yang ingin menggunakan jasa asuransi. Produk asuransi yang ditawarkan pun bermacammacam mulai dari asuransi jiwa, kesehatan, pendidikan sampai tunjangan hari tua (Devis, Khairina, \& Hatta, 2016). Untuk setiap calon nasabah, program asuransi yang mereka butuhkan pastinya berbedabeda, banyaknya pilihan yang dapat diambil dalam menentukan produk asuransi, sebagian besar nasabah atau calon nasabah sering dihadapkan dengan masalah-masalah dalam menentukan produk yang sesuai dengan kebutuhan dan kurangnya pemahaman nasabah terhadap produk-produk yang ditawarkan. Kebanyakan orang akhirnya menyesal setelah masuk asuransi dikarenakan mereka kurang memahami akan kebutuhan mereka didalam berasuransi, sehingga yang terjadi mereka menganggap asuransi tidak bermanfaat (Sunoto \& Susanto, 2017).

Untuk itu dalam memilih produk asuransi yang tepat dan sesuai dengan kebutuhan, diperlukan suatu sistem pendukung keputusan yang dapat mempermudah nasabah dalam mendapatkan informasi serta dapat membantu calon nasabah dalam memahami asuransi agar tidak keliru dalam memilih produk yang ditawarkan dan sesuai dengan kebutuhan masing-masing. Sistem pendukung keputusan merupakan sistem yang dapat digunakan untuk mengambilan keputusan berdasarkan kriteria yang ada. Sistem pendukung keputusan (Decission Support System) adalah sistem pendukung berbasis komputer bagi para pengambil keputusan manajemen yang menangani masalahmasalah yang tidak terstruktur (Kurniawan, Mustafidah, \& Shofiyani, 2015).

Metode yang dipakai dalam analisis pemilihan rekomendasi produk asuransi yang sesuai dengan kebutuhan nasabah adalah metode SAW (Simple Additive weighting). SAW sering juga dikenal sebagai metode penjumlahan terbobot, dari rating kinerja pada setiap alternatif pada semua atribut. Keunggulan dari motode SAW yaitu, metode SAW adalah metode yang paling mudah untuk di aplikasikan, karena mempunyai algoritma yang tidak terlalu rumit (Mufizar, Anwar, \& Aprianis, 2012). Metode ini merupakan metode yang paling terkenal dan paling banyak digunakan dalam menghadapi situasi Multiple Attribute Decission Making (MADM). MADM itu sendiri merupakan suatu metode yang digunakan untuk mencari alternatif optimal dari sejumlah alternatif dengan kriteria tertentu (Safii, 2017).

Pada penelitian sebelumnya (Ananda, Putri, \& Santoso, n.d.) yang berjudul "Sistem Pendukung Keputusan Pemilihan Produk Asuransi Jiwa Perorangan Bagi Calon Nasabah Dengan Menggunakan Metode Profile Matching", sistem berhasil menerapkan Metode Profil Matching untuk pengambilan keputusan pada pemilihan produk asuransi jiwa perorangan dengan mencocokan kompetensi produk asuransi jiwa perorangan dengan kompetensi calon nasabah, maka didapatkan urutan alternatif produk asuransi yang terbaik yang sesuai dengan kualifikasi dan kebutuhan calon nasabah.

Pemilihan rekomendasi produk asuransi dengan menerapkan metode SAW diharapkan dapat membantu dalam pengambilan keputusan rekomendasi produk yang dapat membantu nasabah maupun calon nasabah dalam memilih jenis produk yang sesuai dengan kebutuhan.

\section{Tinjauan Pustaka}

\subsection{Pengertian Produk}

Pada dasarnya produk adalah sesuatu yang ditawarkan oleh produsen pada konsumen untuk memenuhi kebutuhan dan keinginannya (need and wants). Produk bisa berbentuk barang (sesuatu yang berwujud atau tangible), yaitu sesuatu yang berbentuk fisik yang dihasilkan dari proses produksi pada suatu organisasi atau perusahaan. Disamping itu, produk juga 
bisa berupa jasa (sifatnya non-fisik atau intangible) (Heryanto, 2015).

\subsection{Pengertian Sistem}

Menurut (Sunoto \& Susanto, 2017) Sistem merupakan kumpulan elemen yang saling berkaitan yang bertanggung jawab memproses masukan (input), sehingga menghasilkan keluaran (output). Suatu sistem didalam suatu organisasi mempertemukan kebutuhan pengolahan transaksi harian, mendukung operasi, bersifat manajerial dan merupakan kegiatan strategi dari suatu organisasi, serta menyediakan laporan-laporan yang diperlukan oleh pihak luar.

\subsection{Pengertian Sistem Pendukung Keputusan}

Sistem pendukung keputusan (SPK) atau Computer Based Decision Support System (DSS) merupakan salah satu bagian dari sistem informasi yang berguna untuk meningkatkan efektifitas pengambilan keputusan permasalahan yang umum dijadikan objek pada SPK ada yang bersifat semi terstruktur atau terstruktur (Mufizar et al., 2012). Menurut (Ananda et al., n.d.) Sistem pendukung Keputusan adalah suatu sistem informasi berbasis komputer yang dirancang sedemikian rupa untuk membantu pengguna dalam memilih salah satu dari banyak solusi alternatif dari suatu masalah. Tujuan Sistem Pendukung Keputusan.

Tujuan dari sistem pendukung keputusan menurut (Sujarwadi \& Abidin, 2016) dalam (Kusrini, 27) sebagai berikut :

1. Membantu manajer dalam pengambilan keputusan atas masalah semi terstruktur.

2. Memberikan dukungan atas pertimbangan manajer dan bukanya dimaksudkan untuk menggantikan fungsi manajer.

3. Meningkatkan efektivitas yang diambil manajer lebih daripada perbaikan efisiennya.

4. Kecepatan komputasi.

5. Peningkatan Produktivitas.

6. Dukungan kualitas

7. Berdaya saing.

8. Mengatasi keterbatasan kognitif dalam pemrosesan dan penyimpanan.

\subsection{SAW (Simple Additive Weighting)}

Metode SAW mengharuskan pembuat keputusan menentukan bobot bagi setiap atribut. Skor total untuk alternatif diperoleh dengan menjumlahkan seluruh hasil perkalian antara rating (yang dapat dibandingkan lintas atribut) dan bobot tiap atribut (Munir, Marisa, \& Purnomo, 2018).

Metode SAW membutuhkan proses normalisasi matriks keputusan $(X)$ kesuatu skala yang dapat di perbandingkan dengan semua rating alternatif yang ada.

$\operatorname{Rij}=\left\{\begin{array}{l}\frac{x i j}{\max (x i j)} \text { jika } \mathrm{j} \text { adalah atribut (benefit) } \\ \frac{\min (x i j)}{x i j} \text { jika j adalah atribut (cost) }\end{array}\right.$

Dimana rij adalah rating kinerja ternormalisasi dari alternatif Ai pada atribut $\mathrm{Ci} ; \mathrm{I}=1,2, \ldots \mathrm{m}$ dan $\mathrm{j}=1,2, \ldots, \mathrm{n}$. Nilai prefensi alternatif (Vi) diberikan sebagai berikut.

Keterangan :

Rij = Rating kinerja ternormalisasi dari alternatif Ai pada atribut Cj: $i=1,2, \ldots m$ dan $j=1,2, \ldots . n$

$\operatorname{Max} X_{i j}=$ Nilai terbesar dari setiap kriteria $\mathrm{i}$

Min Xij = Nilai terkecil dari setiap kriteria $\mathrm{i}$

Cij = Nilai atribut yang dimiliki dari setiap kriteria

Benefit $=$ Jika nilai terbesar adalah terbaik

Cost =Jika nilai terkecil adalah terbaik

Nilai prefensi untuk setiap alternatif $(\mathrm{Vi})$ Idiberikan rumus sebagai berikut:

$$
V i=\sum_{j=1}^{n} \mathrm{wj} \mathrm{rij}
$$

Keterangan :

$\mathrm{Vi}=$ Rangking untuk setiap alternatif

$\mathrm{Wj}=$ Nilai bobot rangking (dari setiap alternatif)

$\mathrm{Rij}=$ Nilai rating kinerja ternormalisasi

Nilai $\mathrm{Vi}$ yang lebih besar mengdikasikan bahwa alternatif $A$ lebih terpilih.

\subsection{Langkah-langkah SAW}

penyelesaian

1. Menentukan kriteria-kriteria yang akan dijadikan acuan dalam pengambilan keputusan, yaitu $\mathrm{Ci}$.

2. Menentukan rating kecocokan setiap alternatif pada setiap kriteria.

3. Membuat matriks keputusan berdasarkan kriteria (Ci), kemudian melakukan normalisasi matriks 
berdasarkan persamaan yang disesuaikan dengan jenis atribut (atribut keuntungan ataupun atribut biaya) sehingga diperoleh matriks ternormalisasi R.

4. Hasil akhir diperoleh dari proses perankingan yaitu penjumlahan dari perkalian matriks ternormalisasi $R$ dengan vektor bobot sehingga diperoleh nilai terbesar yang diplih sebagai alternatf terbaik $\mathrm{Ai}$ sebagai solusi.

\subsection{Hipotesa}

Dugaan awal atau hipotesa tunggal dari peneltian ini adalah:

HO: Metode SAW tidak dapat menghasilkan keputusan yang akurat dalam memberikan rekomendasi produk asuransi Jiwasraya sesuai kebutuhan nasabah.

H1: Metode SAW dapat menghasilkan keputusan yang akurat dalam memberikan rekomendasi produk asuransi Jiwasraya sesuai kebutuhan nasabah

\subsection{Penelitian Terkait}

Pada penelitian terkait, dilakukan peninjauan kembali berdasarkan jurnal dari penelitian-penelitian yang sebelumnya telah dilakukan, diantaranya:

Penelitian dari (Mufizar et al., 2012) yang berjudul "Sistem Pendukung Keputusan Pemilihan Jurusan Dengan Menggunakan Metode SAW (Simple Additive Weighting) Di SMA 6 Tasikmalaya" menjelaskan bahwa metode SAW mampu mengatasi permasalahan dalam proses pemilihan jurusan dengan menghasilkan keputusan berupa rekomendasi jurusan yang terpilih untuk siswa di SMA 6 Tasikmalaya dengan melakukan penambahan kriteria-kriteria sehingga mampu megurangi subjektifitas, dan berdampak pada hasil pemilihan jurusan diberikan menjadi lebih akurat dan tepat.

Kemudian menurut (Devis et al., 2016) dalam penelitian nya yang berjudul "Sistem Pendukung Keputusan Berbasis Web Untuk Pemilihan produk Asuransi Bagi Calon Nasabah (Weighted Product) (Studi Kasus : PT. Frudential Life Anssurance Samarinda)" dalam pengimplementasian nya dengan menggunakan metode WP kedalam sebuah sistem, memberikan alternatif pilihan tipe produk yang diinginkan oleh pengguna. Sistem menghasilkan alternatif rekomendasi produk asuransi yang sesuai dengan kebutuhan dan keinginan calon nasabah.

Pada penelitian sebelumnya dalam pemilihan rekomendasi produk asuransi yang sesuai untuk calon nasabah, kriteria yang digunakan terdiri dari usia, premi, dan pekerjaan. Sedangkan dalam penelitian kali ini dilakukan penambahan kriteria yang digunakan yaitu terdiri dari usia, manfaat, kegunaan, masa pertanggungan, dan cara bayar. Dengan adanya kriteria tersebut diharapkan dapat memberikan hasil yang lebih efektif dan efisien dalam rekomendasi pemilihan produk asuransi berdasarkan kebutuhan calon nasabah.

\section{Metode Penelitian}

\subsection{Tahapan Penelitian}

Tahapan penelitian mencakup langkah-langkah pelaksanaan penelitian dari awal sampai akhir. Tahapan penelitian dapat dijelaskan sebagai berikut:

\section{a. Start \\ Proses memulai tahapan penelitian \\ b. Identifikasi Masalah}

Setelah mengetahui kriteria-kriteria yang telah ditentukan dalam pemilihan rekomendasi produk asuransi Jiwasraya Cabang Kota Sukabumi serta mengetahui masalah yang sedang dihadapi oleh pihak asuransi, peneliti kemudian merumuskan masalah yang berkaitan dengan permasalahan yang sedang dihadapi oleh PT.Asuransi Jiwasraya Cabang Kota Sukabumi.

c. Pengumpulan Data

Tahap ini merupakan cara pengumpulan data yang dilakukan dengan 2 (dua) cara, yaitu observasi dan wawancara kepada pihak asuransi terkait parameter dalam menentukan pemilihan produk asuransi.

\section{d. Perhitungan Dengan Menggunakan \\ Metode SAW}

Setelah data-data terkumpul kemudian data diolah kedalam metode SAW untuk mengetahui hasil pemilihan rekomendasi produk asuransi berdasarkan kebutuhan calon nasabah PT.Asuransi Jiwasraya Cabang Kota Sukabumi.

\section{e. Hasil Analisis Data}

Setelah ditemukan hasil pemilihan rekomendasi produk asuransi berdasarkan kebutuhan calon nasabah PT. Asuransi Jiwasraya Cabang Kota Sukabumi, dihasilkan satu hasil analisis yang merupakan hasil dari suatu proses 
penelitian yang dilakukan untuk dapat diambil kesimpulannya.

f. Kesimpulan

Tahap kesimpulan merupakan akhir dari penelitian dimana dapat membantu calon nasabah dalam pemilihan rekomendasi produk asuransi yang sesuai dengan keinginan dan kebutuhan.

g. End

Mendapatkan hasil

\subsection{Instrument Penelitian}

Instrumen merupakan alat yang digunakan untuk melakukan sesuatu. Sedangkan penelitian memiliki arti pemeriksaan, penyelidikan, kegiatan pengumpulan, pengolahan, ananlisis dan penyajian data secara sistematis dan obyektif (Rusdiansyah, 2017).

Penelitian ini menggunakan teknik wawancara kepada Kepala Pertanggungan PT. Asuransi Jiwasraya cabang Kota Sukabumi yang berkaitan dengan proses dalam menentukan pemilihan rekomendasi produk asuransi Jiwasraya berdasarkan kebutuhan calon nasabah. Data tersebut meliputi skor dalam pemilihan produk asuransi berdasarkan kriteria usia, manfaat, kegunaan, masa pertanggungan, dan cara bayar.

\subsection{Metode Pengumpulan Data, Populasi dan Sample Penelitian \\ 3.3.1. Metode Pengumpulan Data}

Dalam pembuatan penelitian ini metode pengumpulan data yang digunakan adalah:

\section{Observasi}

Penyusunan skripsi ini melakukan pengumpulan data dengan cara melakukan pengamatan secara langsung mengenai objek yang akan di teliti di Kantor PT. Asuransi Jiwasraya Cabang Kota Sukabumi.

\section{Wawancara}

Penulis melakukan proses tanya jawab dengan Bpk. Fikri Azhari selaku Staff Seksi Pertanggungan dan Bpk. Mochammad Adiet Pranajaya selaku Staff Operasional dan Penjualan sebagai narasumber pada PT.Asuransi Jiwasraya Cabang Kota Sukabumi untuk mendapatkan materimateri serta informasi yang lebih spesifik mengenai penelitian terkait.

3. Studi Pustaka

Dalam penyusunan skripsi ini penulis mengumpulkan data dari berbagai sumber seperti, e-jurnal, buku-buku, website, artikel dan penelitian terkait yang digunakan sebagai studi literatur dalam penelitian. Dan untuk mencari tahu tentang teori-teori pada Metode SAW, rekomendasi pemiliihan produk asuransi, yang medukung penelitian ini agar berjalan dengan semestinya.

\section{Analisa Dokumen}

Dilakukan dengan mempelajari semua dokumen yang berkaitan dengan proses pemilihan produk asuransi yaitu, rekap data penjualan tahun 2018-2019 input data nasabah, form pendaftaran, pengajuan klaim, dokumen tebus, dan lain-lain.

\subsubsection{Populasi}

Populasi adalah wilayah generalisasi yang terdiri atas subyek atau obyek yang mempunyai kualitas dan karakteristik tertentu yang ditetapkan oleh peneliti untuk dipelajari kemudian ditarik kesimpulannya (Mufizar et al., 2012).

Dalam penelitian ini diambil populasi dari jumlah keseluruhan produk asuransi pada PT.Asuransi Jiwasraya. Yang mana data populasi tersebut berjumlah 20 produk asuransi dengan berbagai macam fitur dan manfaat yang berbeda, namun produk yang akan dijadikan populasi dalam penelitian kali ini adalah produk yang diperoleh dari data penjualan pada tahun 2018 pada PT. Asuransi Jiwasraya Cabang Kota Sukabumi yaitu sebanyak 8 produk yang terjual dan paling diminati pada tahun 2018.

\subsubsection{Sampel Penelitian}

Untuk sampel penelitian penulis menggunakan (random sampling) yaitu pegambilan sampel penelitian yang diambil secara acak, degan cara memilih sejumlah item tertentu dari populasi yang ada dengan tujuan mempelajari sebagian item yang ada. Semua item-item di populasi mempunyai kesempatan (Probabilitas) yang sama bagi setiap anggota populasi untuk menjadi sampel penelitian.

Sampel yang digunakan dalam penelitian ini yaitu diambil dari populasi jumlah keseluruhan produk asurasi Pada PT. Asuransi Jiwasraya yang berjumlah 20 produk asuransi namun produk yang paling diminati dan terjual pada tahun 2018 yaitu sebanyak 8 produk. Untuk itu perhitungan yang dilakukan adalah dengan menghitung populasi data dari 8 produk asuransi berdasarkan hasil penjualan pada tahun 2018.

\subsubsection{Metode Analisis Data}


Untuk mencapai tujuan dalam penelitian ini, Metode analisis yang digunakan adalah metode kuantitatif. Analisis Kuantitatif dalam penelitian ini membandingkan kriteria dan alternatif yang bisa menghasilkan sebuah keputusan yaitu pemilihan produk asuransi untuk calon nasabah degan menggunakan metode SAW.

\section{Pembahasan}

\subsection{Analisis Kebutuhan Metode SAW}

PT. Asuransi Jiwasraya sebagai populasi yang akan dijadikan subyek penelitian, adapun produk-produk yang terdapat dalam perusahaan dapat dilihat pada tabel dibawah ini :

Tabel IV.1 Populasi Penelitian

\begin{tabular}{|c|c|}
\hline Nama produk & $\begin{array}{c}\text { Kode } \\
\text { Produk }\end{array}$ \\
\hline Js Prestasi & $\mathrm{A}_{1}$ \\
\hline JsPersonal Accident Plan B & $\mathrm{A}_{2}$ \\
\hline Js Pro Mapan & $\mathrm{A}_{3}$ \\
\hline Js Optima Assurance & $\mathrm{A}_{4}$ \\
\hline Js Dana Multi Proteksi Plus & $\mathrm{A}_{5}$ \\
\hline Js Saving Plan & $\mathrm{A}_{6}$ \\
\hline Js Siharta & $\mathrm{A}_{7}$ \\
\hline Catur Karsa & $\mathrm{A}_{8}$ \\
\hline
\end{tabular}

Sumber: Data Penjualan Produk Asuransi Jiwasraya Tahun 2018

Tabel IV.2 Sampel Penelitian

\begin{tabular}{|c|c|c|}
\hline Nama Produk & $\begin{array}{c}\text { Kode } \\
\text { Produk }\end{array}$ & $\begin{array}{c}\text { Kategori } \\
\text { Produk }\end{array}$ \\
\hline $\begin{array}{c}\text { Js Prestasi } \\
\text { JsPersonal Accident } \\
\text { Plan B }\end{array}$ & $\mathrm{A}_{1}$ & Individu \\
\hline Js Pro Mapan & $\mathrm{A}_{2}$ & Individu \\
\hline Js Optima Assurance & $\mathrm{A}_{3}$ & Individu \\
\hline $\begin{array}{c}\text { Js Dana Multi Proteksi } \\
\text { Plus }\end{array}$ & $\mathrm{A}_{5}$ & Individu \\
\hline Individu \\
\hline Js Saving Plan & $\mathrm{A}_{6}$ & Kumpulan \\
\hline Catur Karsa & $\mathrm{A}_{7}$ & Kumpulan \\
\hline & $\mathrm{A}_{8}$ & Individu \\
\hline
\end{tabular}

Sumber: Data Penjualan Produk Asuransi Jiwasraya Tahun 2018

Adapun hasil penelitian pemilihan rekomendasi produk asuransi Jiwasraya bedasarkan kebutuhan nasabah dengan menggunakan metode Simple Additive Weighting (SAW) dilakukan dengan tujuh tahap, yaitu start, identifikasi masalah, pengumpulan data, analisis data menggunakan metode SAW, hasil analisis data, kesimpulan, end. Hal Pertama yang dilakukan Untuk menyelesaikan pengambilan keputusan berdasarkan perhitungan algoritma SAW, yaitu adalah menentukan nilai kriteria $\mathrm{Cj}$ pada suatu set alternatif $\mathrm{Ai}$, beserta bobot prefensi $(\mathrm{Wj})$ setiap kriteria $\mathrm{Cj}$.

1. Menentukan Kriteria

Menentukan kriteria-kriteria dalam proses pemilihan rekomendasi produk asuransi berdasarkan kebutuhan nasabah. Berikut kriteria yang diperlukan beserta atribut penentuan dalam metode SAW.

Tabel IV.3 Penentuan Kriteria

\begin{tabular}{|c|c|}
\hline Kode & Kriteria \\
\hline C1 & Usia \\
\hline C2 & Manfaat \\
\hline C3 & Kegunaan \\
\hline C4 & Masa pertanggungan \\
\hline C5 & Cara Bayar \\
\hline
\end{tabular}

Tabel IV.4 Penggolongan Kriteria

\begin{tabular}{|c|c|c|}
\hline Kode & Kriteria & Atribut \\
\hline C1 & Usia & Cost \\
\hline C2 & Manfaat & Benefit \\
\hline C3 & Kegunaan & Benefit \\
\hline C4 & Masa pertanggungan & Cost \\
\hline C5 & Cara Bayar & Cost \\
\hline
\end{tabular}

2. Menentukan Nilai Bobot Kriteria (W)

Menentukan bobot pada setiap himpunan kriteria dalam proses rekomendasi pemilihan produk asuransi berdasarkan kebutuhan nasabah. Dari masing-masing kriteria akan ditetukan nilai bobotnya, pembobotan dilakukan berdasarkan tingkat kepentingan pada masing-masing kriteria.

Tabel IV.5 Nilai Bobot Kriteria

\begin{tabular}{|c|c|c|}
\hline Kode & Kriteria & Bobot \\
\hline C1 & Usia & $30 \%$ \\
\hline C2 & Manfaat & $25 \%$ \\
\hline C3 & Kegunaan & $20 \%$ \\
\hline C4 & Masa pertanggungan & $15 \%$ \\
\hline C5 & Cara Bayar & $10 \%$ \\
\hline
\end{tabular}

Tabel VI. 6 Standar Nilai Algoritma SAW 


\begin{tabular}{|c|c|}
\hline Keterangan & Nilai \\
\hline Sangat Rendah (SR) & 1 \\
\hline Rendah (R) & 2 \\
\hline Cukup (C) & 3 \\
\hline Tinggi (T) & 4 \\
\hline Sangat Tinggi (ST) & 5 \\
\hline
\end{tabular}

Adapun kriteria pembobotan yang dilakukan dalam pemilihan rekomendasi produk asuransi adalah sebagai berikut :

a. Skala Penilaian Kriteria Usia

Tabel IV.7 Penilaian Kriteria Usia

\begin{tabular}{|c|c|c|}
\hline Range & Klasifikasi & Rating \\
\hline $0-18$ tahun & Sangat Rendah & 1 \\
\hline $18-32$ tahun & Rendah & 2 \\
\hline $32-45$ tahun & Cukup & 3 \\
\hline $45-70$ tahun & Tinggi & 4 \\
\hline$>70$ tahun & Sangat Tinggi & 5 \\
\hline
\end{tabular}

b. Skala Penilaian Manfaat

Tabel IV.8 Penilaian Manfaat

\begin{tabular}{|c|c|c|}
\hline Range & Klasifikasi & Nilai \\
\hline Akhir Masa Asuransi & Sangat Rendah & 1 \\
\hline Rawat Inap & Rendah & 2 \\
\hline Investasi & Cukup & 3 \\
\hline Kenaikan Asuransi & Tinggi & 4 \\
\hline Meninggal Dunia & Sangat Tinggi & 5 \\
\hline
\end{tabular}

c. Skala Penilaian Kegunaan

Tabel IV.9 Penilaian Kegunaan

\begin{tabular}{|c|c|c|}
\hline Range & Klasifikasi & Nilai \\
\hline Deposito & Sangat Rendah & 1 \\
\hline Pensiunan & Rendah & 2 \\
\hline Pendidikan & Cukup & 3 \\
\hline Investasi & Tinggi & 4 \\
\hline Prroteksi & Sangat Tinggi & 5 \\
\hline
\end{tabular}

d. Skala Penilaian Masa Pertanggungan

Tabel IV.10 Penilaian Masa Pertanggungan

\begin{tabular}{|c|c|c|}
\hline Range & Klasifikasi & Nilai \\
\hline $1-3$ tahun & Sangat Rendah & 1 \\
\hline $4-5$ tahun & Rendah & 2 \\
\hline $10-15$ tahun & Cukup & 3 \\
\hline Sd 99 tahun & Tinggi & 4 \\
\hline Seumur hidup & Sangat Tinggi & 5 \\
\hline
\end{tabular}

Tabel IV.11 Penilaian Cara Bayar

\begin{tabular}{|c|c|c|}
\hline Range & Klasifikasi & Nilai \\
\hline Bulanan & Sangat Rendah & 1 \\
\hline Kuartalan & Rendah & 2 \\
\hline Semesteran & Cukup & 3 \\
\hline Tahunan & Tinggi & 4 \\
\hline Sekaligus & Sangat Tinggi & 5 \\
\hline
\end{tabular}

3. Menentukan Rating Kecocokan Pada

Setiap alternatif

Membuat tabel rating kecocokan dari alternatif A1, A2, A3, A4, A5, A6, A7, A8 dari setiap kriteria.

Tabel IV.12 Rating Kecocokan Dari Data

$$
\text { Awal }
$$

\begin{tabular}{|c|c|c|c|c|c|}
\hline Produk & C1 & C2 & C3 & C4 & C5 \\
\hline $\begin{array}{c}\text { Js } \\
\text { Prestasi }\end{array}$ & $0-18$ & $\begin{array}{c}\text { Kenai } \\
\text { kan } \\
\text { Asura } \\
\text { nsi }\end{array}$ & $\begin{array}{c}\text { Pendidi } \\
\text { kan }\end{array}$ & $10-15$ & $\begin{array}{c}\text { Tahu } \\
\mathrm{n}\end{array}$ \\
\hline $\begin{array}{c}\text { Js } \\
\text { Personal } \\
\text { Accident } \\
\text { Plan B }\end{array}$ & $45-70$ & $\begin{array}{c}\text { Rawat } \\
\text { Inap }\end{array}$ & $\begin{array}{c}\text { Investa } \\
\text { si }\end{array}$ & $1-3$ & $\begin{array}{c}\text { Sekali } \\
\text { gus }\end{array}$ \\
\hline $\begin{array}{c}\text { Js Pro } \\
\text { Mapan }\end{array}$ & $18-32$ & $\begin{array}{c}\text { Invest } \\
\text { asi }\end{array}$ & $\begin{array}{c}\text { Investa } \\
\text { si }\end{array}$ & Sd 99 & $\begin{array}{c}\text { Bulan } \\
\text { an }\end{array}$ \\
\hline $\begin{array}{c}\text { Js } \\
\text { Optima } \\
\text { Assuanc } \\
\text { e }\end{array}$ & $0-18$ & $\begin{array}{c}\text { Invest } \\
\text { asi }\end{array}$ & $\begin{array}{c}\text { Proteks } \\
\text { i }\end{array}$ & $1-3$ & $\begin{array}{c}\text { Sekali } \\
\text { gus }\end{array}$ \\
\hline $\begin{array}{c}\text { Js Dana } \\
\text { Multi } \\
\text { Proteksi } \\
\text { Plus }\end{array}$ & $18-32$ & $\begin{array}{c}\text { Menin } \\
\text { ggal } \\
\text { Dunia }\end{array}$ & $\begin{array}{c}\text { Investa } \\
\text { si }\end{array}$ & Sd 99 & $\begin{array}{c}\text { Kuart } \\
\text { alan }\end{array}$ \\
\hline $\begin{array}{c}\text { Js } \\
\text { Saving } \\
\text { Plan }\end{array}$ & $18-32$ & $\begin{array}{c}\text { Invest } \\
\text { asi }\end{array}$ & $\begin{array}{c}\text { Pensiu } \\
\mathrm{n}\end{array}$ & Sd 99 & $\begin{array}{c}\text { Seme } \\
\text { stera } \\
\mathrm{n}\end{array}$ \\
\hline $\begin{array}{c}\text { Js } \\
\text { Siharta }\end{array}$ & $18-32$ & $\begin{array}{c}\text { Menin } \\
\text { ggal } \\
\text { Dunia }\end{array}$ & $\begin{array}{c}\text { Proteks } \\
\text { si }\end{array}$ & $4-5$ & $\begin{array}{c}\text { Kuart } \\
\text { alan }\end{array}$ \\
\hline $\begin{array}{c}\text { Catur } \\
\text { Karsa }\end{array}$ & $0-18$ & $\begin{array}{c}\text { Invest } \\
\text { asi }\end{array}$ & $\begin{array}{l}\text { Pendidi } \\
\text { kan }\end{array}$ & $10-15$ & $\begin{array}{c}\text { Tahu } \\
\text { nan }\end{array}$ \\
\hline
\end{tabular}

Dari Tabel IV.12 diatas, selanjutnya akan dibentuk rating kecocokan dari setiap alternatif seperti pada tabel IV.13 dibawah ini.

e. Skala Penilaian Cara Bayar

JURNAL SWABUMI Vol. 9 No.2, September 2021: 175-184 
Tabel IV.13 Rating Kecocokan alternatif

\begin{tabular}{|c|c|c|c|c|c|}
\hline \multirow{2}{*}{ Alternatif } & \multicolumn{5}{|c|}{ Kriteria } \\
\cline { 2 - 6 } & \multirow{2}{*}{ C1 } & C2 & C3 & C4 & C5 \\
\hline$A_{1}$ & 1 & 4 & 3 & 3 & 4 \\
\hline$A_{2}$ & 4 & 2 & 4 & 1 & 5 \\
\hline$A_{3}$ & 2 & 3 & 4 & 4 & 1 \\
\hline$A_{4}$ & 1 & 3 & 5 & 1 & 5 \\
\hline$A_{5}$ & 2 & 5 & 4 & 4 & 2 \\
\hline$A_{6}$ & 2 & 3 & 2 & 4 & 3 \\
\hline$A_{7}$ & 2 & 5 & 5 & 2 & 2 \\
\hline$A_{8}$ & 1 & 3 & 3 & 3 & 4 \\
\hline
\end{tabular}

4. Membuat Matriks Keputusan (x)

Membuat matriks keputusan yang dibentuk dari tabel rating kecocokan,yaitu sebagai berikut :

$$
X=\left[\begin{array}{lllll}
1 & 4 & 3 & 3 & 4 \\
4 & 2 & 4 & 1 & 5 \\
2 & 3 & 4 & 4 & 1 \\
1 & 3 & 5 & 1 & 5 \\
2 & 5 & 4 & 4 & 2 \\
2 & 3 & 4 & 2 & 3 \\
2 & 5 & 5 & 2 & 2 \\
1 & 3 & 3 & 3 & 4
\end{array}\right]
$$

5. Membuat Matriks Keputusan

Ternormalisasi (R)

Melakukan normalisasi matriks keputusan $X$ dengan cara menghitung nilai rating kinerja ternormalisasi (Rij) dari alternatif (Ai) pada kriteria $(\mathrm{Cj})$.

Perhitungan dilakukan sebagai berikut :
a. Kriteria Usia
b. Kriteria Manfaat
c. Kriteria Kegunaan
d. Masa Pertanggungan
e. Kriteria Cara Bayar

Dari hasil perhitungan persamaan diatas, maka didapatkan sebuah nilai matriks ternormalisasi $(R)$ yaitu sebagai berikut :

$$
\mathrm{R}=\left[\begin{array}{ccccc}
1 & 0,8 & 0,6 & 0,33 & 0,25 \\
0,25 & 0,4 & 0,8 & 1 & 0,2 \\
0,5 & 0,6 & 0,8 & 0,25 & 1 \\
1 & 0,6 & 1 & 1 & 0,2 \\
0,5 & 1 & 0,8 & 0,25 & 0,5 \\
0,5 & 0,6 & 0,8 & 0,5 & 0,33 \\
0,5 & 1 & 1 & 0,5 & 0,5 \\
1 & 0,6 & 0,6 & 0,33 & 0,25
\end{array}\right]
$$

6. Menghitung Nilai Prefensi (Vi)

Setelah didapat hasil dari normalisasi, maka selanjutnya membuat perkalian matriks (prefensi) untuk mendapatkan perangkingan dari seluruh alternatif. Diketahui bobot nilai $W=[30,25,20,15,10]$

$$
\begin{aligned}
& \mathrm{V} 1=(30)(1)+(25)(0,8)+(20)(0,6)+ \\
& (15)(0,33)+(10)(0,25)=69,5 \\
& \mathrm{~V} 2=(30)(0,25)+(25)(0,4)+(20)(0,8)+ \\
& (15)(1)+(10)(0,2)=50,5 \\
& \mathrm{~V} 3=(30)(0,5)+(25)(0,6)+(20)(0,8)+ \\
& (15)(0,25)+(10)(1)=59,75 \\
& \mathrm{~V} 4=(30)(1)+(25)(0,6)+(20)(1)+(15)(1)+ \\
& (10)(0,2)=82 \\
& \mathrm{~V} 5=(30)(0,5)+(25)(1)+(20)(0,8)+ \\
& (15)(0,25)+(10)(0,5)=64,75 \\
& \text { V6 }=(30)(0,5)+(25)(0,6)+(20)(0,8)+ \\
& (15)(0,5)+(10)(0,33)=56,8 \\
& \mathrm{~V} 7=(30)(0,5)+(25)(1)+(20)(1)+ \\
& (15)(0,5)+(10)(0,5)=72,5 \\
& \mathrm{~V} 8=(30)(1)+(25)(0,6)+(20)(0,6)+ \\
& (15)(0,33)+(10)(0,25)=64,5
\end{aligned}
$$

7. Hasil Perangkingan

Untuk mengetahui produk yang sesuai dengan kebutuhan calon nasabah maka dilakukan proses perangkingan berdasarkan hasil akhir dengan nilai terbesar sebagai alternatif terbaik. Berikut hasil perangkingan pada setiap alternatif :

Tabel IV.14 Hasil perangkingan

\begin{tabular}{|c|c|c|}
\hline iNama Produk & $\begin{array}{c}\text { Kode } \\
\text { Produk }\end{array}$ & $\begin{array}{c}\text { Hasil } \\
\text { Perangkingan }\end{array}$ \\
\hline Js Prestasi & A1 & 69,45 \\
\hline $\begin{array}{c}\text { JsPersonal Accident } \\
\text { Plan B }\end{array}$ & A2 & 50,5 \\
\hline Js Pro Mapan & A3 & 59,75 \\
\hline Js Optima Assurance & A4 & 82 \\
\hline $\begin{array}{c}\text { Js Dana Multi } \\
\text { Proteksi Plus }\end{array}$ & A5 & 64,75 \\
\hline Js Saving Plan & A6 & 56,8 \\
\hline Js Siharta & A7 & 72,5 \\
\hline Catur Karsa & A8 & 64,45 \\
\hline
\end{tabular}

\subsection{Hasil Analisis Data}

Dari proses tersebut diperoleh hasil akhir perhitungan dan perkalian matriks , dapat disimpulkan bahwa yang memperoleh nilai tertinggi adalah V4 sehingga alternatif A4 adalah alternatif yang terpilih sebagai atlernatif terbaik dan V2 pada alternatif A2 sebagai alter natif terendah. Dapat disimpulkan bahwa produk asuransi Js Optima Assurance dengan nilai 82 dan nilai terendah yaitu produk asuransi Js Personal Accident Plan B dengan nilai 50,5. Maka produk asuransi yang sesuai dengan kebutuhan nasabah dapat di urutkan dari nilai tertiggi ke nilai terendah yaitu sebagai berikut: 
Tabel IV.15 Pengurutan Hasil Perangkingan

\begin{tabular}{|c|c|c|}
\hline \multicolumn{3}{|c|}{ Perangkingan } \\
\hline Nama Produk & $\begin{array}{c}\text { Kode } \\
\text { Produk }\end{array}$ & $\begin{array}{c}\text { Hasil } \\
\text { Perangkingan }\end{array}$ \\
\hline $\begin{array}{c}\text { Js Optima } \\
\text { Assurance }\end{array}$ & A4 & 82 \\
\hline Js Siharta & A7 & 72,5 \\
\hline Js Prestasi & A1 & 69,45 \\
\hline $\begin{array}{c}\text { Js Dana Multi } \\
\text { Proteksi Plus }\end{array}$ & A5 & 64,75 \\
\hline Js Catur Karsa & A8 & 64,45 \\
\hline Js Pro Mapan & A3 & 59,75 \\
\hline Js Saving Plan & A6 & 56,8 \\
\hline $\begin{array}{c}\text { Js Personal } \\
\text { Accident Plan B }\end{array}$ & A2 & 50,5 \\
\hline
\end{tabular}

\section{Penutup}

Kesimpulan yang dapat diambil dari keseluruhan penelitian ini adalah sebagai berikut :

1. Metode SAW dapat menghasilkan keputusan yang akurat dalam memberikan rekomendasi produk asuransi Jiwasraya sesuai kebutuhan nasabah.

2. Didapatkan urutan produk asuransi dari yang tertinggi sampai terendah untuk memudahkan calon nasabah dalam memilih produk yang sesuai dengan kebutuhan yaitu, Js Optima Assurance 82, Js Siharta 72,5, Js Prestasi 69,45, Js Dana Multi Proteksi Plus 64,75, Catur Karsa 64,45, Js Pro Mapan 59,75, Js Saving Plan 56,8, dan Js Personal Accident Plan B 50,5.

3. produk Js Optima Assurance terpilih sebagai solusi alteratif terbaik dengan memperoleh nilai tertinggi yaitu 82 .

4. Berdasarkan Hipotesa $\mathrm{H} 1$ yaitu Metode Simple Additive Weighting (SAW) dapat mengatasi permasalahan yang ada di PT.Asuransi Jiwasraya Cabang Kota Sukabumi dalam pengambilan keputusan pemilihan rekomendasi produk asuransi berdasarkan kebutuhan nasabah.

Peneliti menyarankan pengembangan penelitian lebih lanjut dalam sistem penunjang keputusan pemilihan rekomendasi produk asuransi yaitu:

1. Penelitian ini dapat dikembangkan kedalam aplikasi berbasis web ataupun online sehingga penerapan nya lebih beragam dan dapat digunakan dalam ruang lingkup yang lebih luas.

2. Diharapkan agar dapat menjadi sumber referensi dan bahan pembelajaran untuk melakukan pelitian pada perusahaan asuransi dengan objek berbeda lainya dan tidak hanya pemilihan produk asuransi.

3. Diperlukan kriteria tambahan agar keakurasian pengambilan keputusan lebih baik.

4. Sistem pendukung keputusan pemilihan rekomendasi produk asuransi dapat dikembangkan dengan metode selain SAW, misalnya seperti metode WP, AHP, TOPSIS, dll sebagai pembanding sehingga mendapat hasil perangkingan yang semakin akurat.

\section{Referensi}

Ananda, N., Putri, N., \& Santoso, N. (n.d.). SISTEM PENDUKUNG KEPUTUSAN PEMILIHAN PRODUK.

Devis, W., Khairina, D. M., \& Hatta, H. R. (2016). Sistem Pendukung Keputusan Berbasis Web Untuk Pemilihan Produk Asuransi Bagi Calon Nasabah ( Weighted Product ) ( Studi Kasus : PT . Prudential Life Anssurance Samarinda ).

Gunawan, A. (2014). SISTEM PENDUKUNG KEPUTUSAN UNTUK MENENTUKAN PRODUK BRIngin DanaDwiguna, untuk kesehatan dan BRIngin Investama, untuk kesehatan dan investasi, 12(1), 73-79.

Heryanto, I. (2015). Analisis pengaruh produk, harga, distribusi, dan promosi terhadap keputusan pembelian serta implikasinya pada kepuasan pelanggan, 9(2), 80-101.

Kurniawan, E., Mustafidah, H., \& Shofiyani, A. (2015). Metode TOPSIS untuk Menentukan Penerimaan Mahasiswa Baru Pendidikan Dokter di Universitas Muhammadiyah Purwokerto ( TOPSIS Method to Determine New Students 
Admission at Medical School in University of, III(November), 201206.

Mufizar, T., Anwar, D. S., \& Aprianis, E. (2012). Sistem Pendukung Keputusan Pemilihan Jurusan Dengan Menggunakan Metode SAW ( Simple Additive Weighting ) Di SMA 6 Tasikmalaya Decision Support System Of Major Selection Using Saw Method In SMA 6 Tasikmalaya, 1-13.

Munir, M., Marisa, F., Purnomo, D., Teknik, F., Informatika, T., \& Malang, U. W. (2018). MAHASISWA PENERIMA BEASISWA DENGAN METODE SIMPLE ADDITIVE, 10(2), 32-40.

Safii, M. (2017). SISTEM PENDUKUNG KEPUTUSAN PENERIMA BEASISWA PPA DAN BBM MENGGUNAKAN METODE SIMPLE ADDITIVE WEIGHTING ( SAW ), 31(1), 75-83.

Sujarwadi, A., \& Abidin, D. Z. (2016). PERANCANGAN SISTEM PENDUKUNG KEPUTUSAN DENGAN METODE SIMPLE ADDITIVE WEIGHTING ( SAW ) DALAM PENENTUAN TUNJANGAN KINERJA PEGAWAI, 1(1), 54-66.

Sunoto, I., Susanto, A., Informatika, T., Teknik, F., \& Barat, T. (2017). SISTEM KEPUTUSAN PENDUKUNG ASURANSI PEMILIHAN MENGGUNAKAN ANALYTIC METODE PROCESS, 9(1). 